\title{
Exploration of Crucial Factors Involved in Plants Development Using the Fuzzy AHP Method
}

\author{
Hemant Upadhyay $\mathbb{D}^{1},{ }^{1}$ Abhinav Juneja $\mathbb{D}^{2},{ }^{2}$ Hamza Turabieh $\mathbb{D}^{3},{ }^{3}$ Sapna Malik, ${ }^{4}$ \\ Ankur Gupta (D), ${ }^{5}$ Zelalem Kiros Bitsue ${ }^{(D)}{ }^{6}$ and Chanchal Upadhyay ${ }^{7}$ \\ ${ }^{1}$ BMIET, Sonepat, India \\ ${ }^{2}$ KIET Group of Institutions, Delhi NCR Ghaziabad, India \\ ${ }^{3}$ Department of Information Technology, College of Computing and Information Technology, Taif University, P.O. Box 11099, \\ Taif 21944, Saudi Arabia \\ ${ }^{4}$ Maharaja Surajmal Institute of Technology, Delhi, India \\ ${ }^{5}$ Bennett University, Greater Noida, India \\ ${ }^{6}$ United States of African Health Organization, Ethiopia \\ ${ }^{7}$ Department of Botany, Faculty of Life Sciences, Dr. B.R. Ambedkar University, Agra, India
}

Correspondence should be addressed to Zelalem Kiros Bitsue; bitsue.zelalem29@gmail.com

Received 14 December 2021; Revised 13 January 2022; Accepted 22 January 2022; Published 27 February 2022

Academic Editor: Naeem Jan

Copyright (c) 2022 Hemant Upadhyay et al. This is an open access article distributed under the Creative Commons Attribution License, which permits unrestricted use, distribution, and reproduction in any medium, provided the original work is properly cited.

\begin{abstract}
Remarkable changes in the environment have been impacting the production ability of plants. Few variation strategies are available to adapt for the outcomes of environmental changes such as maximum and minimum temperature in the development phase of the plants. A large portion of the plants expresses affectability to saltiness of the dirt. Considering the tediousness of various kinds, it is needful to perceive the possible obstructions in plants development. However, it has been observed that critical factors in plants development are required to be explored. The prime objective of this current work is for analysis of the chosen critical factors in plants development. Nine critical factors in plants development are shortlisted from the extensive literature reviewing in three categories, "climate factors", "terrestrial factors", and "human factors" with the help of experts' inputs. Fuzzy analytical hierarchy process (FAHP) methodology has been selected for ranking of critical factors in plants development. Raw information is gathered from an online survey from twenty-five botanists, academicians, researchers, and agriculture scientists. The results may become very helpful in the strategy in developing efficient planning for dealing with critical factors in plants development.
\end{abstract}

\section{Introduction}

The growth of plants and their development are controlled by several conditions, climate and the environment. In other words, plant growth and geographical distribution are greatly influenced by climate and climatic conditions. In one way or the other, most problems of the plants are due to climate stresses, and the chief climatic factor of plant growth is affected by light, rainfall, heat, and availability or lack of water [1]. As per O. S. University, four things affecting the development of plants are the availability of light, deficiency of water, and amount of heat and nutrients. Growth is a permanent, irreversible increase of an organism. This characteristic is observed in almost all plants with many metabolic type processes. It is a known fact that seed germination develops new seedling for eventual development into a mature plant and exhibits indefinite growth [2]. Plant cells are interconnected by rigid walls, setting their positions in relation to each other, and causing a mechanical reaction between cells [3]. Plants development is accomplished by a number of chemical and physical processes that are controlled by climate factors such as light, water, temperature, oxygen, and carbon dioxide. 
When some fluctuations in these climate factors start, then it directly affects the plant's growth; especially, heat is a highly influencing factor [4]. Plants with prolonged water pressure or inadequate nutrition will be weak and may have abnormal leaves, flowers, or fruits. If climate stress occurs even for a short period of time at an important stage of development, the plant may never express its full genetic potential. Climate is an influencing aspect of managing the distribution of species. Plants are with two strategies as avoidance and resistance [5]. Several plants develop in the winter season, during which they also take up nutrients. Due to an increase in temperature during summer, difficulties also arise in morphological and metabolic activities in plants.

1.1. Plant Growth Stages. When we think about the beginning of a new plant, our attention turns to the seed. A seed is a plant in a dormant state, inside which its life system remains closed. This system also contains the embryo of the plant and a sufficient amount of food material to keep it alive, which crosses its germination and early life. Different stages of plant growth have been shown in Figure 1.

1.1.1. Germination. Every seed consists of a tiny stash of nutrients that are required for germination and growing their initial set of leaves. Basically, it is the phase of the plant's growth cycle that is responsible for plant reproduction.

1.1.2. Sowing. As plant roots develop and spread, nutrients develop fast from initial seedling to adult plants. The seedling stage is where the plant develops from seed to change into roots, stems, and leaves.

1.1.3. Vegetative. Nitrogen is a major element of chlorophyll and is an important nutrient. The vegetative stage is when the plant germinates and produces its initial green tendencies. It happens about 1-8 weeks after sowing the seeds.

1.1.4. Shooting. There is an additional demand for phosphorus at the beginning of the reproduction cycle of the plant, from the development of leaves to buds.

1.1.5. Blooming. Potassium has the initial role in the production and transport of plants of sugars and starches which develop healthy fruits. In the blooming stage, plants prepare themselves to produce fruit or flowers.

The paper has been settled as the critical review of recent work was carried out in Section 2. Method applied in the presented work is explained in Section 3. The factors in plants development are identified and represented in Section 4. Analysis of data interpretation and result is shown in Section 5. Finally, the conclusion statement is communicated with future possibilities.

\section{Review of the Literature}

Plants need resources and suitable conditions for them to grow so that these resources can be converted into biomass [6]. Heat is an initial factor influencing the pace of plant growth. Normal temperatures increased the rate of phonological growth; however, it shows a negligible impact on the leaves area. The main influence of higher temperatures comes in the reproduction stage of growth. Heat influencing elements are enhanced by deficiency of water showing that the interaction of heat and water is needed for influential adaptation tactics for offsetting the effects of high temperature [4].

Salinity is one of the most severe environmental factors limiting the productivity of crop plants because of the high concentrations that are sensitive to salinity [7]. The entire life cycle of the plant is highly affected by the light surroundings [8]. Agriculture-based plants exhibit a set of reactions with the salt stress. Salinity reduces the agricultural production of most plants and further affects soil physicochemical characteristics and the ecology-based balance of the region. For all important plants, mean yields are only a part-between one fourth and half of the record yields; such losses are because of drought and soil salinity [7].

From the literature survey, it is obvious that the assessment of important factors in plants development is a complicated task to be dealt with. Thus, it is necessary to recognize critical factors in plants development. The next section explains with recognition of critical factors in plants development. Table 1 collects remarkable past research efforts in the exploration of the factors in plant growth.

\section{Methodology}

Analysis of the critical factors in plants development has been done with the fuzzy analytical hierarchy process (FAHP). Nine factors in plants development have been sorted from extensive review, validated from experts' opinions, and categorized into three categories as "climate factors", "terrestrial factors", and "human factors" as shown in Table 2.

Fuzzy AHP, that is, fuzzy analytical hierarchical process, is a hierarchy-based process; therefore, it is the best suited multicriteria decision-making technique for our study with a two-level categorized structure. A web-based survey was also done with inputs from 30 botanists, academicians, researchers, agriculture scientists, using Google form to take the unbiased inputs to understand the priorities of the botanists, academicians, researchers, agriculture scientists. This survey response has been duly used as a weight in the ranking of factors. Thereafter, the fuzzy AHP technique has been employed in ranking these essential factors as per the research framework shown in Figure 2.

Fuzzy systems, including fuzzy set theory and fuzzy logic, provide a rich and meaningful improvement or extension of traditional logic [10]. The FAHP method, which harnesses human cognition and decision power based on knowledge and experience, is applied and used for decision making. The priorities related to each major cause and 


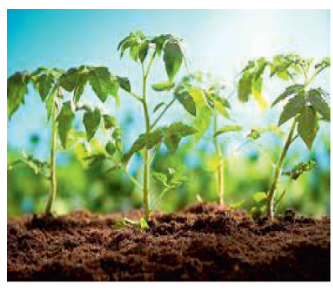

Germination

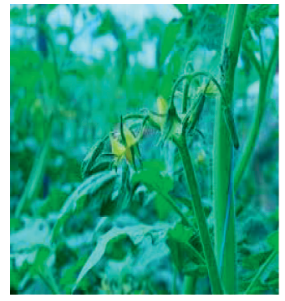

Sowing

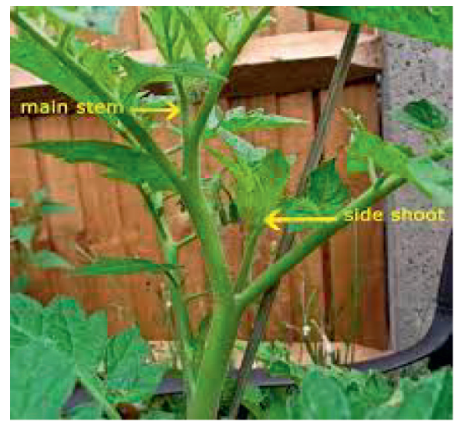

Vegetative

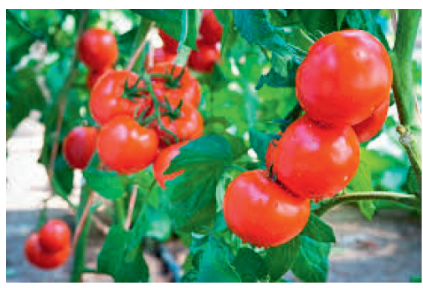

Shooting

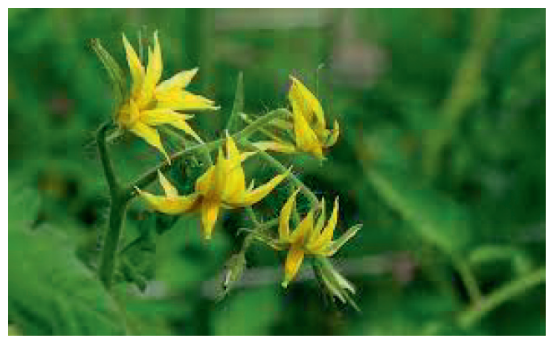

Blooming

Figure 1: Different growth stages of the plant.

subcause can be used to decide on improvement projects and their order due to scarce resources [11].

In other words, the FAHP approach is a practical and convenient way to show potential areas for implementing effective management strategies, especially in areas where data availability is low [12]. Fuzzy AHP was developed to solve the hierarchical fuzzy issues [13]. The first fuzzy AHP method was presented by van Laarhoven and Pedrycz [14]. Buckley's technique [15] is applied to compute the relative weightages for options as well as criteria in fuzzy AHP.

Triangular fuzzy numbers are settled with the three real numbers $(l, m, u)$, consisting of the triangle numbers " $l$ ", " $m$ ", and " $n$ " as the least, the most, and the largest probable value, respectively [16] (Table 3 ).

Analysis of data and results are provided in Section 5.

\section{Identification of Critical Factors in Plants Development}

To obtain the main objective of our research work that is the exploration of critical factors in plants development, various research papers published were reviewed. There are several factors that affect the plants development directly or indirectly. Figure 3 displays the overall scheme corresponding to the complete hierarchical structure of factors taken in the current research work. There are two major factors that affect the plants development directly or indirectly.

Nine critical factors in plants development have been sorted from the contributed research and expert's inputs as "light", "temperature", "stresses", "water", "drought", "soil", "pollution", "fertilizers", and "deforestation". Nine factors in plants development are subcategorized into two levels ("climate factors", "terrestrial factors", and "human factors") as mentioned below.

4.1. Climate Factors. The main factors those influence plants development include light, heat, water, humidity, and nutrition. It is essential to know how these barriers impact plants development. With knowledge of such barriers, we are able for manipulation of plants to fulfill the requirements, whether to increase the production of leaves or fruits. By identifying the roles of such barriers, it may be better to sort out plant issues due to climate stress.

4.1.1. Light. Light is a huge resource of energy and the chief ecology-based factor influencing plants development. Light stands out among the environmental factors that shape plants development, but sometimes, its extreme level distracts plant growth [17]. Variability in character tics of light influences the development of plants. Photosynthesis is the process that changes optical energy into chemical. Light is essential for photosynthesis. Every green plant needs light for its development. Few plants do grow in direct sunlight, and on the other hand, others do grow in indirect sunlight. Plants developed in greenhouses need proper light in photosynthesis. Photosynthesis process rate reduces during cloudbased weather. But, all plants do not need high light quality. Shade plants need very less sunlight for optimized development, but high light becomes the reason for sunburn and even death in an extreme situation in the absence of enough moisture in the soil. 
TABLE 1: Latest research of critical factors in plants development.

\begin{tabular}{ccc}
\hline SN & Author & Objective and outcome \\
\hline 1 & $\begin{array}{c}\text { Hatfield et al. } \\
\text { (2015) }\end{array}$ & $\begin{array}{c}\text { The authors concluded that water will be required for development of more influential adaptation tactics for } \\
\text { offsetting the influences of greater heat extreme events related with a modifying climate. They suggested that } \\
\text { variability in precipitation associated with hot temperatures will enhance the adverse impact on grain } \\
\text { productivity [4]. }\end{array}$ \\
& $\begin{array}{r}\text { The authors took two soybean cultivars subjected to three different water treatments for two week. With drought } \\
\text { stresses, the decrease in shoot biomass was much pronounced than the decrease of biomass in the root of both } \\
\text { soybean cultivars, dealing in high root/shoot proportions [9]. }\end{array}$ \\
\hline
\end{tabular}

TABle 2: Different categories of crucial factors involved in plants development.

\begin{tabular}{lc}
\hline Crucial factors categories & \\
\hline Category 1 & Climate factors \\
Category 2 & Terrestrial factors \\
Category 3 & Human factors \\
\hline
\end{tabular}

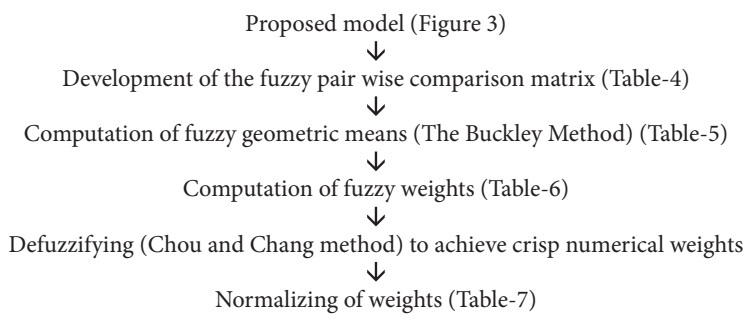

FIGURE 2: The research framework used in this paper.

4.1.2. Temperature. Plant processes such as photosynthesis, transpiration, respiration, germination, and flowering are affected by temperature. Warmer temperatures expected with climate change and the potential for more extreme temperature events will impact plant productivity [4]. Heat influences the change from leafy to reproduction growth. The temperature may be managed at an adequate level by cooling and heating systems, inside propagation chambers [18]. The temperature is useful in enhancing the humidity in the chambers. Managing heat at a particular level may enhance plant quality. Optimized development of several plants occurs while greenhouse temperatures are having less temperature during the night than the day [19]. Higher heat controls biology reactions due to the obstruction of complicated structures of proteins. Though respiration as well as photosynthesis may carry on gradually at temperatures less than $32^{\circ} \mathrm{F}$ when less temperature contribute in defining the length of the active development duration [20]. The development duration for annual seeded crops has the frostfree duration, the number of weeks between the final day with the least temperatures below $32^{\circ} \mathrm{F}$ in the spring and the opening day with the least temperatures below $32^{\circ} \mathrm{F}$ during the fall.

4.1.3. Stresses. Stress in crops deals with external situations which adversely influence the development or productivity of plants [21]. A plant stress generally reflects a few sudden modifications in the climate situation. Crop stress may be divided into two classifications as abiotic stress and biotic stress. Abiotic stress imposed on crops by surrounding can be chemical or physical, as biotic stress exposed to the plants is a biology unit like diseases [22].

4.2. Terrestrial Factors. Multiple adverse phenomena may have a detrimental and lethal impact on crops in natural situations, for instance, asphyxiation under stresses, drought, flood, and humidity.

4.2.1. Water. Most developing crops consist of more than 90 percentage water. Water has several roles in crops. This is a basic element in photosynthesis and respiration and a solvent for minerals and carbohydrates moving through the plant. Water-deficient situations during summer are not often. The summer season constitutes the primary duration of productivity for a variety of plant communities [23]. Rainy season experiences water scarcity situations much more than half the time. Water availability and precipitation act along to influence the physiology and ecology status of a variety of crops. The rainfall determines a plant's biological water potential status. Plant in water stress has restricted development and decreased photosynthetic rate, reduced plant vigor, decreased carbohydrate storage, decreased root biomass, and decreased plant height [24].

4.2.2. Drought. Drought is concerned with a variety of crop responses. Plants development is affected, with modification in the architecture of people, which are transformed in low height, decreased leaf size, a small quantity of leaves, and limited fruit products and modifications in the reproduction phase. Drought and heat stresses are important threat limitations to plant growth and sustainable agriculture worldwide [25]. In agriculture ecosystem, drought is having a detrimental impact on plant productivity, influencing the development rate of the portions of the plant. Drought stress in crops is specified by decreased leaves water and reduced cell development and enhancement [25]. Drought stress decreases the plants development by affecting several physiological and biochemical activities like nutrient metabolism and carbohydrates metabolism [26].

4.2.3. Soil. Soil structuring influences crop development in several ways. Roots develop very fast in the friable nature of the soil, but their uptake of nutrients and water can be controlled by proper contact with the different phases of the soil. Such contacting is very intimating in harder soil, and further, the 
TABLE 3: Linguistic scale for triangular fuzzy numbers and reciprocal.

\begin{tabular}{lrrr}
\hline Satty scale & Linguistic scale for relative importance & Fuzzy triangular scale & Corresponding reciprocal \\
\hline 1 & Equally important & $(1,1,1)$ & $(1,1,1)$ \\
3 & Weakly important & $(2,3,4)$ & $(1 / 4,1 / 3,1 / 2)$ \\
5 & Fairly important & $(4,5,6)$ & $(1 / 6,1 / 5,1 / 4)$ \\
7 & Strongly important & $(6,7,8)$ & $(1 / 8,1 / 7,1 / 6)$ \\
9 & Absolutely important & $(9,9,9)$ & $(1 / 9,1 / 9,1 / 9)$ \\
2 & & $(1,2,3)$ & $(1 / 3,1 / 2,1)$ \\
4 & & $(3,4,5)$ & $(1 / 5,1 / 4,1 / 3)$ \\
6 & The intermediate values between two adjacent scale & $(5,6,7)$ & $(1 / 7,1 / 6,1 / 5)$ \\
8 & & $(7,8,9)$ & $(1 / 9,1 / 8,1 / 7)$ \\
\hline
\end{tabular}

\begin{tabular}{|l|l|l|}
\cline { 2 - 3 } \multicolumn{1}{c|}{} & \multicolumn{3}{c|}{ Critical Factors in Plants } \\
\hline CLIMATE & TERRESTRIAL & HUMAN \\
FACTORS & FACTORS & FACTORS \\
1. LIGHT (CB1) & 1. WATER (TB1) & 1. POLLUTION (HB1) \\
2. TEMPERATURE (CB2) & 2. DROUGHT (TB2) & 2. FERTILIZERS (HB2) \\
3. STRESSES (CB3) & 3. SOIL (TB3) & 3. DEFORESTATION (HB3) \\
\cline { 2 - 4 } & &
\end{tabular}

FIgURE 3: The proposed hierarchical model to analyze critical factors in plants development.

development of the roots is highly inhibited for poor foraging capability and nutrients deficient plants. The physiochemical characteristics of the soil are said as edaphic elements of the plant surroundings. The physical characteristics such as the soil texture, soil structure, and bulk density influence the capacity of the soil for retaining water, when the chemical characteristics contain the soil $\mathrm{pH}$. The prime influences are on root development, which is highly inhibited by harder soil, and this impacts the capability of the root system for the extraction of proper nutrients from the soil and water. Much subtle impact happens in soil which is harder, and consisting fissures by that roots develops gradually.

4.3. Human Factors. For the last couple of years, it has been observed that human activity is accountable for climate change. Farmers may incorporate fertilizers for preparing plants to develop at a high pace. The public harm plants in several ways like deforestation, pollution, forest fires, and tarnishing soil and water.

4.3.1. Pollution. Particular focus on the pollutants $\left(\mathrm{SOx}, \mathrm{O}_{3}\right.$, and NOx) may modify the physiological processing of plants, influencing patterns of development. Air pollutants are responsible for damage to leaves cuticles. These may have considerable influences on photosynthetic structure, leaves longevity. Polluted water in the field does wash the necessary nutrition that is required by plants from the soil. In absence of such nutrients, plants may be much prone to drought, several infections, and insects. Water pollutants always leave a huge quantity of aluminum in the soil which is very dangerous for plants.

4.3.2. Fertilizers. Fertilizers may be termed as materials that consist of plant nutrients that are mixed in the surroundings around a plant by adding in the water, soil, and spraying on leaves. Such a methodology is known as foliar fertilization. Plants do the production of their own food through photosynthesis, and it has plant nutrients for the production of proteins, enzymes, vitamins, etc. If a crop has very less fertilizers, then plant growth will be very poor, and on the other hand, fertilizer excess may slow down plants development because of the thick probability of root damage or death due to high fertilizer salts.

4.3.3. Deforestation. Deforestation leads to biodiversity loss while animal species living in the trees lose their habitat. It becomes a reason for the disappearance of certain tree species. Studies have suggested that more than hundred plants, animals, and insect species are being lost daily because of rainforest deforestation while the loss of species is very instrumental for life-threatening diseases.

\section{Results}

Based on the ratings obtained through a web-based survey regarding critical factors in plants development, the fuzzy pair-wise comparative matrix is shown in Table 4 .

The values in boxes in Table 4 denote trio of lower value, middle value, and upper value that will be later converted into crisp numeral value.

The geometric average of fuzzy comparative values of every factor is computed as mentioned in Table 5. Furthermore, computed sums and respective reciprocals are shown in the table itself. We know that the fuzzy triangle structured numbers must be in enhancing order, and the sequence of the numbers is changed as in the final row of Table 5 .

The relative fuzzy weightages of each critical factor have been tabulated in Table 6 . 
TABLe 4: The fuzzy PWC matrix for critical factors in plants development.

\begin{tabular}{lccccccccc}
\hline & CB1 & CB2 & CB3 & TB1 & TB2 & TB3 & HB1 & HB2 & HB3 \\
\hline CB1 & $(1,1,1)$ & $(3,4,5)$ & $(9,9,9)$ & $(1 / 3,1 / 2,1)$ & $(5,6,7)$ & $(1,2,3)$ & $(6,7,8)$ & $(4,5,6)$ & $(3,4,5)$ \\
CB2 & $(1 / 5,1 / 4,1 / 3)$ & $(1,1,1)$ & $(5,6,7)$ & $(1 / 6,1 / 5,1 / 4)$ & $(2,3,4)$ & $(1 / 4,1 / 3,1 / 2)$ & $(3,4,5)$ & $(1,2,3)$ & $(1,1,1)$ \\
CB3 & $(1 / 9,1 / 9,1 / 9)$ & $(1 / 7,1 / 6,1 / 5)$ & $(1,1,1)$ & $(1 / 9,1 / 9,1 / 9)$ & $(1 / 5,1 / 4,1 / 3)$ & $(1 / 9,1 / 8,1 / 7)$ & $(1 / 4,1 / 3,1 / 2)$ & $(1 / 6,1 / 5,1 / 4)$ & $(1 / 7,1 / 6,1 / 5)$ \\
TB1 & $(1,2,3)$ & $(4,5,6)$ & $(9,9,9)$ & $(1,1,1)$ & $(6,7,8)$ & $(2,3,4)$ & $(7,8,9)$ & $(5,6,7)$ & $(4,5,6)$ \\
TB2 & $(1 / 7,1 / 6,1 / 5)$ & $(1 / 4,1 / 3,1 / 2)$ & $(3,4,5)$ & $(1 / 8,1 / 7,1 / 6)$ & $(1,1,1)$ & $(1 / 6,1 / 5,1 / 4)$ & $(1,2,3)$ & $(1 / 3,1 / 2,1)$ & $(1 / 4,1 / 3,1 / 2)$ \\
TB3 & $(1 / 3,1 / 2,1)$ & $(2,3,4)$ & $(7,8,9)$ & $(1 / 4,1 / 3,1 / 2)$ & $(4,5,6)$ & $(1,1,1)$ & $(5,6,7)$ & $(3,4,5)$ & $(2,3,4)$ \\
HB1 & $(1 / 8,1 / 7,1 / 6)$ & $(1 / 5,1 / 4,1 / 3)$ & $(2,3,4)$ & $(1 / 9,1 / 8,1 / 7)$ & $(1 / 3,1 / 2,1)$ & $(1 / 7,1 / 6,1 / 5)$ & $(1,1,1)$ & $(1 / 4,1 / 3,1 / 2)$ & $(1 / 5,1 / 4,1 / 3)$ \\
HB2 & $(1 / 6,1 / 5,1 / 4)$ & $(1 / 3,1 / 2,1)$ & $(4,5,6)$ & $(1 / 7,1 / 6,1 / 5)$ & $(1,2,3)$ & $(1 / 5,1 / 4,1 / 3)$ & $(2,3,4)$ & $(1,1,1)$ & $(1 / 3,1 / 2,1)$ \\
HB3 & $(1 / 5,1 / 4,1 / 3)$ & $(1,1,1)$ & $(5,6,7)$ & $(1 / 6,1 / 5,1 / 4)$ & $(2,3,4)$ & $(1 / 4,1 / 3,1 / 2)$ & $(3,4,5)$ & $(1,2,3)$ & $(1,1,1)$ \\
\hline
\end{tabular}

TABLE 5: Geometric average of fuzzy comparative values.

\begin{tabular}{lccc}
\hline Geometric means & & & \\
\hline Light (CB1) & 2.455 & 3.147 & 3.936 \\
Temperature (CB2) & 0.857 & 1.102 & 0.208 \\
Stresses (CB3) & 0.183 & 4.255 & 0.243 \\
Water (TB1) & 3.401 & 0.504 & 5.001 \\
Drought (TB2) & 0.385 & 2.244 & 0.680 \\
Soil (TB3) & 1.732 & 0.357 & 2.913 \\
Pollution (HB1) & 0.287 & 0.735 & 0.467 \\
Fertilizers (HB2) & 0.545 & 1.102 & 1.020 \\
Deforestation (HB3) & 0.857 & 13.654 & 1.374 \\
Sum & 10.702 & 0.0732 & 17.008 \\
Reciprocal & 0.0934 & 0.0732 & 0.0588 \\
Increasing order & 0.0588 & & 0.0934 \\
\hline
\end{tabular}

TABLE 6: Relative fuzzy weightages of each critical factor.

\begin{tabular}{llll}
\hline Relative fuzzy weightages & & & \\
\hline Light (CB1) & 0.144 & 0.230 & 0.368 \\
Temperature (CB2) & 0.050 & 0.081 & 0.128 \\
Stresses (CB3) & 0.011 & 0.015 & 0.023 \\
Water (TB1) & 0.200 & 0.311 & 0.467 \\
Drought (TB2) & 0.023 & 0.037 & 0.064 \\
Soil (TB3) & 0.102 & 0.164 & 0.272 \\
Pollution (HB1) & 0.017 & 0.026 & 0.044 \\
Fertilizers (HB2) & 0.032 & 0.054 & 0.095 \\
Deforestation (HB3) & 0.050 & 0.081 & 0.128 \\
\hline
\end{tabular}

Relative crisp numeral weightage of every critical factor (Mi) is calculated by considering the average of fuzzy numbers for every factor. Finally, relative crisp numeral weights of every critical factor are normalized as $\mathrm{Ni}$ as mentioned in Table 7.

Total nine critical factors in plants development in three categories ("climate factors", "terrestrial factors", and "human factors") have been compared in Table 8. This comparison shows in terms of priorities and their ranking.

Table 8 shows the rank of the several factors using fuzzy AHP. Based on the numerical values expressed in Table 8 , water $(0.304)$ has been proved the most influential factor in plants development followed by light (0.230) and soil (0.167), and on the other hand, stresses (0.016) are the least influential factor.
Figure 4 presents the weightage of the various factors using fuzzy AHP. Total three categories ("climate factors", "terrestrial factors", and "human factors") have been compared in Table 9. Human factors have the least priority.

Based on the numerical values mentioned in Table 9, "terrestrial factors" are ranked at the highest place followed by "climate factors". Figure 5 presents the weightage of the various categories using fuzzy AHP in pie chart form.

In the full $360^{\circ}$ circle diagram, weightage of all three chosen categories of factors has been shown as per their respective priority values. These factor values have been presented in different hues.

The outcomes of the work by a few of the potential efforts are summarized in Table 10. Furthermore, our present work has been compared side by side. 
TABLe 7: Average and normalized relative weightage of factors.

\begin{tabular}{lcr}
\hline & $\mathrm{Mi}$ & $\mathrm{Ni}$ \\
\hline Light (CB1) & 0.247 & 0.230 \\
Temperature (CB2) & 0.086 & 0.080 \\
Stresses (CB3) & 0.017 & 0.016 \\
Water (TB1) & 0.326 & 0.304 \\
Drought (TB2) & 0.042 & 0.039 \\
Soil (TB3) & 0.179 & 0.167 \\
Pollution (HB1) & 0.029 & 0.027 \\
Fertilizers (HB2) & 0.061 & 0.057 \\
Deforestation (HB3) & 0.086 & 0.080 \\
\hline
\end{tabular}

TABLE 8: Factors priority results.

\begin{tabular}{lccc}
\hline Categories & Issues & Priority & Rank \\
\hline & Light (CB1) & 0.230 & $2 \mathrm{nd}$ \\
Climate factors & Temperature (CB2) & 0.080 & 4 th \\
& Stresses (CB3) & 0.016 & 8 th \\
Terrestrial factors & Water (TB1) & 0.304 & 1 st \\
& Drought (TB2) & 0.039 & 6 th \\
& Soil (TB3) & 0.167 & 3 rd \\
Human factors & Pollution (HB1) & 0.027 & 7 th \\
& Fertilizers (HB2) & 0.057 & 5 th \\
\hline
\end{tabular}

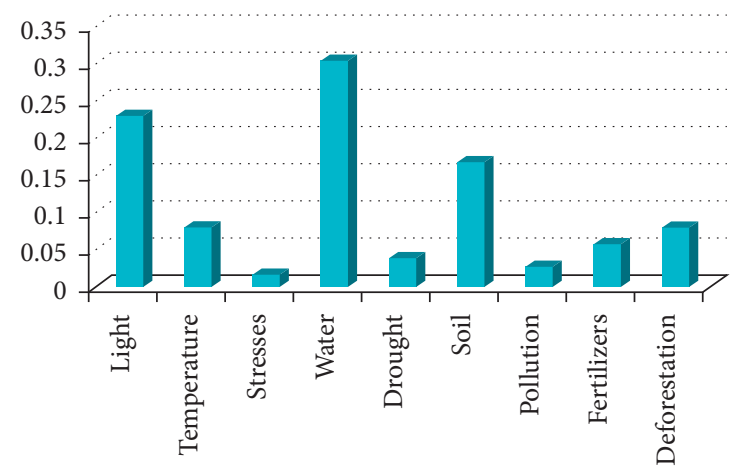

FIGURE 4: Priorities of different factors.

TABLE 9: Category priority results.

\begin{tabular}{lcc}
\hline Category & Priority & Rank \\
\hline Climate factors & 0.326 & IInd \\
Terrestrial factors & 0.510 & Ist \\
Human factors & 0.164 & III rd \\
\hline
\end{tabular}




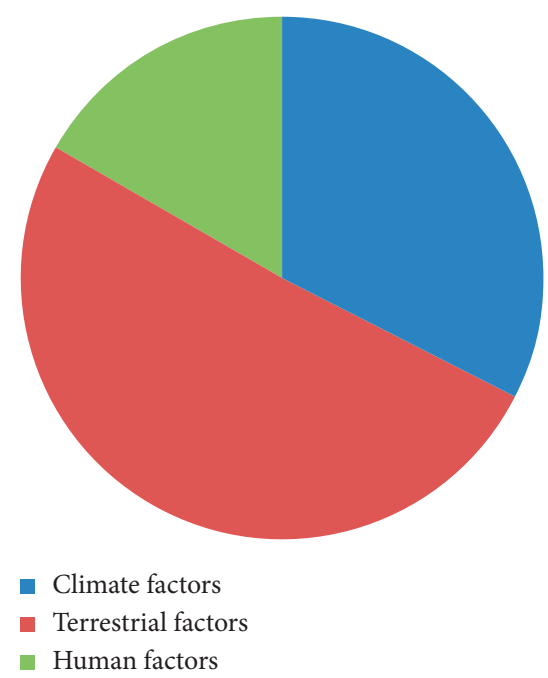

FIGURE 5: Weightage of different categories.

TABLE 10: Comparison of our research work with few contributions.

\begin{tabular}{|c|c|c|c|}
\hline $\mathrm{SN}$ & Paper & Outcome & Present work \\
\hline 1 & $\begin{array}{l}\text { Hatfield et al. } \\
\qquad(2015)\end{array}$ & $\begin{array}{c}\text { Authors concluded that water will be required for } \\
\text { development of much influential adaptation strategies } \\
\text { for offsetting the influences of high heat events associated } \\
\text { with climate change [4]. }\end{array}$ & $\begin{array}{l}\text { Our study identified the critical factors in plants } \\
\text { development as "light", "temperature", "stresses"; "water", } \\
\text { "drought", "soil"; "pollution", "fertilizers", } \\
\text { "deforestation". }\end{array}$ \\
\hline 2 & $\begin{array}{l}\text { Du et al. } \\
(2020)\end{array}$ & $\begin{array}{c}\text { Author concluded that with drought stresses, the } \\
\text { decrease in shoot biomass becomes much important than } \\
\text { the decrease of biomass in the root of both soybean } \\
\text { cultivars [8]. }\end{array}$ & $\begin{array}{l}\text { Nine factors in plants development, sub categorized in two } \\
\text { levels ("climate factors", "terrestrial factors", "human } \\
\text { factors") have been compared and ranked by fuzzy AHP } \\
\text { method to explore possible aspects to address the factors } \\
\text { in plants development. }\end{array}$ \\
\hline 3 & $\begin{array}{l}\text { Orhan mete } \\
\text { et al. }(2021)\end{array}$ & $\begin{array}{l}\text { They revealed that fuzzy AHP is an applicable and } \\
\text { effective approach to take more effective decisions in } \\
\text { agricultural issues [19]. }\end{array}$ & $\begin{array}{l}\text { We utilized fuzzy AHP for recognition and comparative } \\
\text { study and ranking of barriers in the growth of the several } \\
\text { plants. }\end{array}$ \\
\hline
\end{tabular}

\section{Conclusions and Future Work Scope}

This work has shown an MCDM method for assessment of critical factors in plants development using fuzzy AHP technique, considering nine factors ("light", "temperature", "stresses", "water", "drought", "soil", "pollution", "fertilizers", and "deforestation"). Total nine critical factors in plants development in three different categories have been compared and ranked. The current research work has shown that the possible aspects can be a key to address the critical factors in plants development. It is obviously evident from the finding of the present work that "water" has emerged as the most critical factor in plants development followed by "light" and "soil". Furthermore, "terrestrial factors" have been ranked first place followed by "climate factors".

Some other multicriteria decision-making techniques with different adequate statistical tools like structural equation modeling technique can become instrumental for such problems, and the outputs can be compared. Best worst method, analytic network process, "decisionmaking trial and evaluation laboratory" technique, and "technique for order of preference by similarity to ideal solution" methods may be very useful for similar issues in different disciplines.

\section{Data Availability}

The data will be made available from the author Hemant Upadhyay upon request (hementdeo@gmail.com).

\section{Conflicts of Interest}

The authors declare that they have no conflicts of interest.

\section{Authors' Contributions}

Hemant Upadhyay performed conceptualization and formal analysis and developed the methodology; Sapna Malik wrote the initial draft; Abhinav Juneja wrote the original draft and performed supervision. Hamza Turabieh performed visualization and performed project administration; Ankur Gupta performed formal analysis, reviewed, and edited the article. Chanchal Upadhyay performed the final supervision 
of the paper. Zelalem Kiros Bitsue performed the final review of the article.

\section{Acknowledgments}

The authors would like to acknowledge Taif University Researchers Supporting Project (TURSP-2020/125), Taif University, Taif, Saudi Arabia.

\section{References}

[1] R. Rötter and S. C. Van De Geijn, "Climate change effects on plant growth, Crop yield and livestock," Climatic Change, vol. 43 , no. 4, pp. 651-681, 1999.

[2] K. David, "Plant cells: cell division and cell differentiation," Encyclopedia of Applied Plant Sciences, vol. 1, 2 edition, 2017.

[3] K. Keegstra, "Future perspectives in plant biology: plant cell walls," Plant Physiology, vol. 154, no. 2, pp. 483-486, 2010, http://www.plantphysiol.org/cgi/.

[4] J. L. Hatfield and J. H. Prueger, "Temperature extremes: effect on plant growth and development," Weather and Climate Extremes, vol. 10, pp. 4-10, 2015.

[5] J. Kreyling, "Winter climate change: a critical factor for temperate vegetation performance," Ecology, vol. 91, no. 7, pp. 1939-1948, 2010.

[6] C. Körner, "Paradigm shift in plant growth control," Current Opinion in Plant Biology, vol. 25, pp. 107-114, 2015.

[7] P. Shrivastava and R. Kumar, "Soil salinity: a serious environmental issue and plant growth promoting bacteria as one of the tools for its alleviation," Saudi Journal of Biological Sciences, vol. 22, no. 2, pp. 123-131, 2015.

[8] L. Qian and C. Kubota, "Effects of supplemental light quality on growth and phytochemicals of baby leaf lettuce," Climate and Experimental Botany, vol. 67, pp. 59-64, 2009.

[9] Y. Du, Q. Zhao, L. Chen et al., "Effect of drought stress on sugar metabolism in leaves and roots of soybean seedlings," Plant Physiology and Biochemistry, vol. 146, pp. 1-12, 2020.

[10] A. B. McBratney and I. O. A. Odeh, "Application of fuzzy sets in soil science: fuzzy logic, fuzzy measurements and fuzzy decisions," Geoderma, vol. 77, no. 2-4, pp. 85-113, 1997.

[11] A. Shaygan and Ö. M. Testik, "A fuzzy AHP-based methodology for project prioritization and selection," Soft Computing, vol. 23, no. 4, pp. 1309-1319, 2019.

[12] S. G. Meshram, E. Alvandi, V. P. Singh, and C. Meshram, "Comparison of AHP and fuzzy AHP models for prioritization of watersheds," Soft Computing, vol. 23, Article ID 13615, 2019.

[13] ş. Özdagoglu and G. Özdagoglu, "Comparison of AHP and fuzzy AHP for the multicriteria decision making processes with linguistic evaluations," pp. 65-85, 2007.

[14] P. J. M. Van Laarhoven and W. Pedrycz, "A fuzzy extension of Saaty"s priority Theory," Fuzzy Sets and Systems, vol. 11, no. 13, pp. 199-227, 1983.

[15] J. J. Buckley, "Fuzzy hierarchical analysis," Fuzzy Sets and Systems, vol. 17, no. 1, pp. 233-247, 1985.

[16] F. D. Wicaksono, Y. B. Arshad, and H. Sihombing, "Normdist Monte-Carlo integrative method for the improvement of fuzzy analytic hierarchy process," Heliyon, vol. 6, Article ID e03607, 2020.

[17] D. Alabadí and M. A. Blázquez, "Molecular interactions between light and hormone signaling to control plant growth," Plant Molecular Biology, vol. 69, 2009.

[18] L. Lipiec, G. DoussaN, A. Nosalewicz, and K. Kondracka, "Effect of drought and heat stresses on plant growth and yield: a review," Environnement Méditerranéen et Modélisation des Agro-Hydrosystèmes, vol. 27, 2021 https://hal.archivesouvertes.fr/hal-01318641.

[19] M. K. Orhan, K. Ersayın, H. Gunal, A. Khalofah, and M. S. Alsubeie, "Combination of fuzzy-AHP and GIS techniques in land suitability assessment for wheat (Triticum aestivum) cultivation," Saudi Journal of Biological Sciences, 2021.

[20] C. Shao, Y. Yang, S. Juneja, and T. GSeetharam, "IoT data visualization for business intelligence in corporate finance," Information Processing \& Management, vol. 59, no. 1, 2022.

[21] A. Juneja, S. Juneja, S. Kaur, and V. Kumar, "Predicting diabetes mellitus with machine learning techniques using multicriteria decision making," International Journal of Information Retrieval Research, vol. 11, no. 2, pp. 38-52, 2021.

[22] A. Juneja, S. Juneja, V. Bali, and S. Mahajan, "Multi-criterion decision making for wireless communication technologies adoption in IoT," International Journal of System Dynamics Applications, vol. 10, no. 1, pp. 1-15, 2020.

[23] S. Juneja, A. Juneja, and R. Anand, "Healthcare 4.0-digitizing healthcare using big data for performance improvisation," Journal of Computational and Theoretical Nanoscience, vol. 17, no. 9-10, pp. 4408-4410, 2020.

[24] A. Juneja, S. Juneja, A. Soneja, and S. Jain, "Real time object detection using CNN based single shot detector model," Journal of Information Technology Management, vol. 13, no. 1, pp. 62-80, 2021.

[25] S. Agrawal, S. Sarkar, M. Alazab, P. K. R. Maddikunta, T. R. Gadekallu, and Q.-V. Pham, "Genetic CFL: hyperparameter optimization in clustered federated learning," Computational Intelligence and Neuroscience, vol. 2021, Article ID 7156420, 10 pages, 2021.

[26] S. Agrawal, A. Chowdhuri, S. Sarkar, R. Selvanambi, and T. R. Gadekallu, "Temporal weighted averaging for asynchronous federated intrusion detection systems," Computational Intelligence and Neuroscience, vol. 2021, Article ID 5844728, 10 pages, 2021. 